\section{Questión}

Periodismo / Comunicación ISSN 1669-6581
- Av. $44 \mathrm{~N}^{\circ} 676,1^{\circ}$ piso

CP 1900 - La Plata - Argentina

(4) www.perio.unlp.edu.ar/question

LA CALAMIDAD ES UN BAILE SIN FIN. La danza de la muerte en el cine de pandemias

Pedro Arturo Gómez

DOI: https://doi.org/10.24215/16696581e293

\title{
LA CALAMIDAD ES UN BAILE SIN FIN
}

La danza de la muerte en el cine de pandemias

\section{CALAMITY IS AN ENDLESS DANCE}

The Dance of Death in Pandemic Cinema

Pedro Arturo Gómez / pearg050@gmail.com Docente e investigador en la Carrera de Ciencias de la Comunicación y la Escuela Universitaria de Cine, Video y TV, Universidad Nacional de Tucumán (UNT), en la Carrera de Comunicación Social, de la Universidad Católica de Santiago del Estero (UCSE). Master en Lingüística. Se especializa en Comunicación Audiovisual, Estudios Culturales y

Semiótica. 


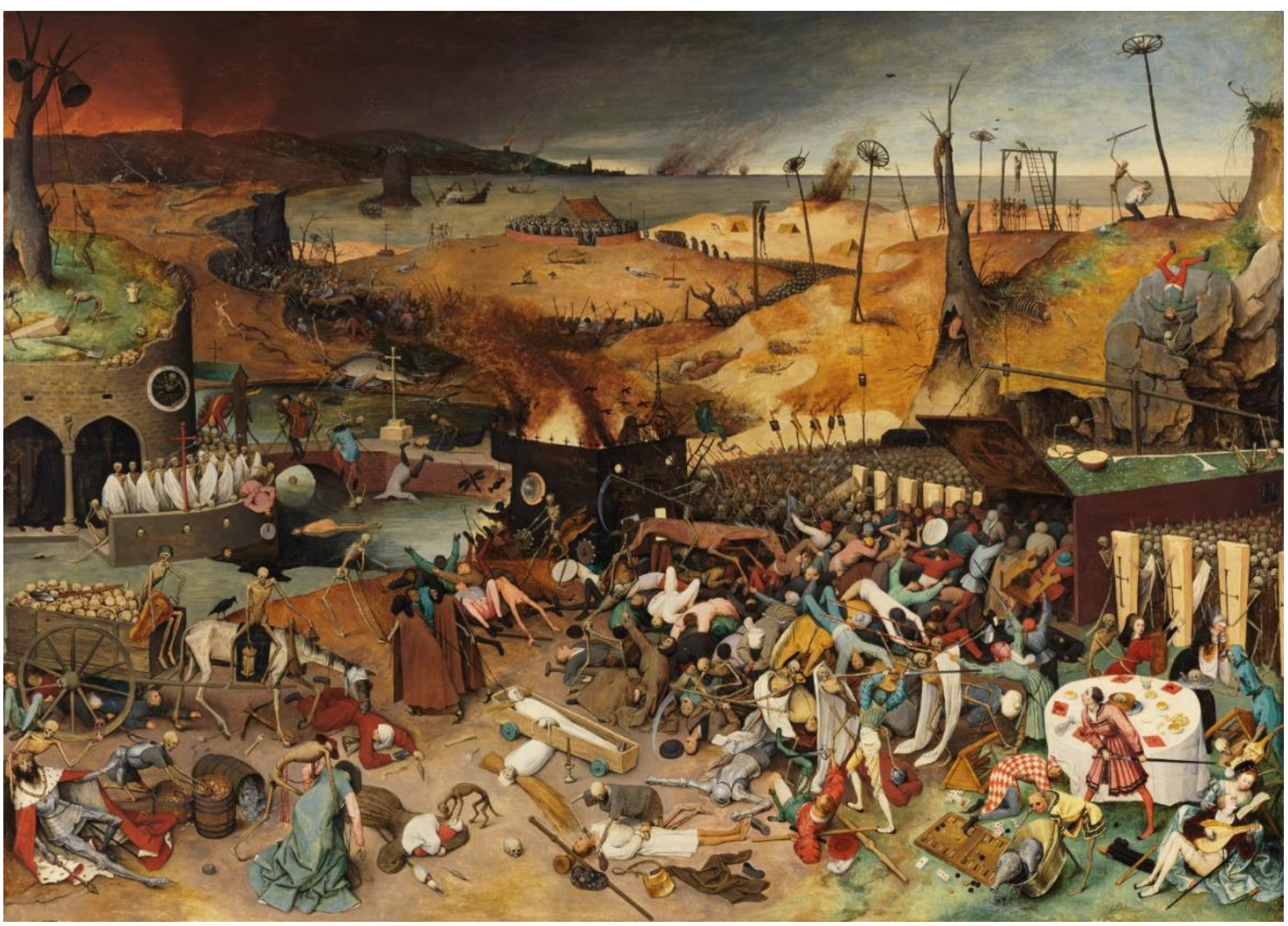

"El triunfo de la muerte" de Pieter Brueghel el Viejo (1525 -1569), célebre pintura de la Escuela Flamenca del siglo XVI, es la expresión más apabullante de los horrores de la llamada "peste negra" que diezmó a Europa y Asia en el siglo XIV, la pandemia más devastadora en la historia de la humanidad. El óleo de $117 \mathrm{~cm}$ de alto $\times 162 \mathrm{~cm}$ de ancho se ve abarrotado con minuciosidad por las atrocidades del pandemónium viral, al son de la "danza de la muerte", uno de los tópicos recurrentes de la tardía Edad Media: hordas de esqueletos arrasando multitudes y campos reinan sobre un mundo devastado. Dinamismo abigarrado, detallismo realista y elementos fantásticos se combinan para lograr la principal cualidad de la obra: un efecto de estremecedora tangibilidad. La catástrofe ha sido siempre una atracción hipnótica, donde se conjugan la seguridad de la contemplación distanciada y la pavorosa adrenalina de la experiencia. El cine con sus atributos de inmersión sensorial ha llevado esos rasgos a una contundencia sublime. 
La tradicional ansiedad existencial por la fragilidad humana ante las formas más espantosas de la muerte se ha transformado, dentro de la cultura postmoderna del espectáculo, en fuente de fantasías que erotizan el desastre, explotadas por los medios de comunicación y las industrias del entretenimiento. Las patologías de la razón desplegadas en la constante conflictividad bélica, la degradación del medioambiente y las tecnologías del exterminio estimulan un núcleo de miedo que hace temblar la fe en el progreso científico y la democracia, con Estados siempre carcomidos por tentaciones autoritarias y el totalitarismo capitalista. Todos estos fermentos nutren una sensibilidad cultural seducida por la calamidad y una imaginación orientada hacia la crisis, motores generadores de ficciones que estimulan la fascinación por la hecatombe. El resultado es que las catástrofes son hoy objetos de la cultura de masas.

Los desastres hacen la historia y las historias, en un mundo donde las grandes desgracias nos ofrecen un vislumbre de lo real y los relatos del placer por el pánico nos permiten vivir esas desgracias con una posibilidad de control y distanciamiento, como escudo de protección contra los males verdaderos. Las narraciones de cataclísmicos padecimientos en mundos distópicos muy cercanos a nuestra realidad funcionan como cuentos morales que exponen la extrema vulnerabilidad de lo humano, sus miserias y las zonas más oscuras del poder, pero también las potencias del sacrificio en la lucha por la supervivencia y el vigor de los lazos afectivos, porque las calamidades son movilizadoras de la acción, ponen en marcha una cadena de acontecimientos donde no dejan de aflorar continuas oportunidades de condena y redención. El cine de catástrofe no sólo permite una visualización del desastre en su mayor esplendor, sino que se muestra también como un espejo radical de la condición humana expuesta en sus límites, cierto que dentro de un patrón regido por las leyes del espectáculo.

Las enfermedades pandémicas han sido el trasfondo en varios filmes de la edad de oro de Hollywood, como Jezebel (William Wyler, 1938) -la fiebre amarilla- Arrowsmith (John Ford, 1931) -la peste bubónica- y The Painted Veil (Richard Boleslawski, 1934) -el cólera- entre otras. Pero es recién a partir del último tercio del siglo XX que el tema ha ascendido a una centralidad en las producciones cinematográficas, sobre todo en el mainstream estadounidense, dentro del género de catástrofe. El cine de pandemias se divide en dos vertientes principales: thrillers con elementos de ciencia ficción -donde las más sobresalientes son La amenaza de Andrómeda (The Andromeda Stream, Robert Wise, 1971), Epidemia (Outbreack, Wolfgang Petersen, 1995) y Contagio (Contagion, Steven Soderbergh, 2011)- y 
películas de zombies, a partir de Exterminio (28 Days Later, Danny Boyle, 2002), en la cual los zombies ya no son los tradicionales muertos reanimados, sino personas infectadas por un virus.

El principal problema para esta temática en el cine -resuelto magistralmente en el arte pictórico por una obra como "El triunfo de la muerte"- es el lograr una tangibilidad contundente en la representación de un mal en principio invisible, que se toma su tiempo para manifestarse, a contrapelo del despliegue hiperbólico característico del género catástrofe, reacio a demorarse en la temporalidad y en los detalles científicos y médicos que un tema como el de las pandemias entraña. La amenaza de Andrómeda -en la que un equipo de científicos se enfrenta a un virus extraterrestre que ha arrasado a un pueblo entero- resuelve este problema a base de suspenso, concentrando un reducido grupo de personajes y tribulaciones a contrarreloj en el espacio claustrofóbico de un laboratorio de alta tecnología ubicado en el interior de un bunker subterráneo. La peripecia intensa es la opción que toma Epidemia, dirigida por un especialista en el cine de acción como es Wolfgang Petersen, con una frenética lucha entre el bien y el mal -librada hasta en persecuciones y duelos aéreos de helicópteros y un avión bombarderodonde los héroes son los científicos enfrentados no sólo a un feroz virus hemorrágico, sino también a un militar que encarna los intereses del ejército por usar el microorganismo como arma biológica. La figura de este villano incorpora una mayor dosis de tangibilidad física a la representación de las fuerzas del mal, además de la visualización de los estragos corporales que provoca la enfermedad, en una película donde la verdadera plaga es lo implausible de elementos como el de un mono capuchino, especie natural de América Central y del Sur, que aparece como el portador de un virus originado en África, y el desarrollo en minutos de la vacuna con efectos de cura instantánea. Por su parte, Contagio es valorada hoy -casi diez años después de su estreno- como el film de mayor correspondencia con la realidad de una pandemia, por su rigor en el manejo de los datos y procedimientos científicos, sin incurrir en las desproporciones típicas de la espectacularidad. No obstante, esto que es su cualidad más notable puede ser a la vez un inconveniente, ya que la sobriedad de la narración le da, a pesar de su buen ritmo, un generalizado tono monocorde apenas roto por la inserción algo forzada de la subtrama del secuestro de una agente de la OMS y de una secuencia de home invasion protagonizada por la pareja de un directivo de esa misma institución, además de cierto tinte moralista que se desprende del hecho de que el personaje que desencadena el contagio 
masivo es una mujer adúltera. Es así que esta obra de un realizador tan eclético e irregular como Soderbergh queda atrapada en una de las tensiones vertebrales del cine, la que existe entre la relación con la realidad (el efecto de realismo) y la sujeción a las reglas del género (la catástrofe como espectáculo). Dentro de esta misma vertiente, pero alejada totalmente de la sobriedad, la película coreana Flu (Kim Sung Soo, 2013) apela a la acumulación cuantitativa y la sobrecarga melodramática para pintar la enormidad del caos provocado en una ciudad cercana a Seúl por el brote de un virus aéreo, conjugando el padecimiento colectivo e individual de las víctimas con las manipulaciones del poder político, en las que el gobierno local sufre el intervencionismo de una potencia internacional cuyo idioma es -muy significativamente- el inglés.

En la senda marcada por la seminal La noche de los muertos vivientes (Night of the Living, George Romero, 1968) -con sus secuelas, precuelas y remakes- apegadas a sus propias convenciones, las películas de zombies tienen más asegurada la visualización dinámica de los horrores de la peste, materializados en el equivalente a las turbas de esqueletos en la pintura de Brueghel: las muchedumbres de infectados, que se mueven con una letalidad aún más veloz que la expansión de cualquier virus. De este modo se genera una impresión de realismo que no tiene que ver con la correspondencia de los filmes con la realidad de las pandemias, sino con un efecto de tangibilidad autocontenida que absorbe en su propia lógica a los espectadores, a la vez que los sustrae de la dimensión real de las infecciones pandémicas. La globalización de la pandemia y la masividad de los contagios son hechas visibles en grado superlativo por la grandilocuencia de una superproducción como World War Z (Marc Forster, 2013). La desolación de los espacios públicos devastados y la soledad del aislamiento en los escenarios del apocalipsis zombie aparecen en películas como Exterminio, en la que un personaje despierta sin información alguna en una Londres postapocalíptica, tomada por humanos presas de una rabia voraz resultado de la liberación de un virus mutante artificial; y las versiones cinematográficas de Soy leyenda, la novela de Richard Matheson: El último hombre sobre la Tierra (The Last Man on Earth, Ubaldo Ragona y Sidney Salkow, 1964), The Omega Man (Boris Sagal, 1971) y Soy leyenda (I Am Legend, Francis Lawrence, 2007), donde un científico, único sobreviviente de una plaga que convierte a los seres humanos en zombies vampiros, se debate buscando una cura encerrado en su refugio, del que sale sólo bajo la luz del día a recorrer solitario la ciudad desierta, mientras duermen los infectados que vagan al 
acecho durante la noche. Variaciones de este mismo esquema aparecen en numerosas películas, ya con acento en la acción y el terror gráfico, ya con mayor énfasis en el suspenso y el drama personal, entre las que se destacan Cargo (Ben Howling y Yolanda Ramke, 2017), Maggie (Henry Hobson, 2015), The Girl with All the Gifts (Colm McCarthy, 2016), Pandemic (John Suits, 2016), la franquicia Resident Evil, It Comes at Night (Trey Edward Shults, 2017) y la estupenda producción coreana Tren a Busan / Estación zombie (Busanhaeng, Yeon Sangho, 2016); además de series televisivas como The Walking Dead (2010, en curso), su derivada Fear the Walking Dead (2015, en curso) y Z Nation (2014-2018). También han tenido éxito comedias de zombies entre las que sobresalen Shaun of the Dead (Edgar Wright, 2004) y Zombieland (Ruben Fleischer, 2009).

Relieves particulares tiene la mixtura de road movies (películas de carretera) con el subgénero de pandemias, con zombies en el caso de -por ejemplo- The Battery (Jeremy Gardner, 2012), o sin ellos como en Portadores (Carriers, Àlex y David Pastor, 2009), o en la comedia existencial con toques de humor absurdo Tóxico (Ariel Martínez Herrera, 2020), película argentina que se adelantó unos cuantos meses a la crisis del COVID-19, con su historia de una pareja munida de barbijos, alcohol en gel y medicamentos traficados, que a bordo de su casa rodante atraviesan un mundo barrido por una epidemia de insomnio.

En su conjunto, las películas sobre pandemias son la materialización audiovisual de obras pictóricas como "El triunfo de la muerte", aunque las más de las veces recortadas según los moldes del entretenimiento industrial, con obediencia debida a las convenciones del género de catástrofe. Como tales, son productos que responden a la libidinización del desastre, en sus aspectos culturales y comerciales, manufacturados para el consumo a gran escala, de ahí la estandarización que erosiona la calidad artística de sus formas y contenidos. En el mejor de los casos, el manejo de sus mecanismos puede arrojar piezas para un logrado disfrute cuyo eje está en el placer de bailar distanciadamente la danza de la muerte. La calamidad puede ser un baile sin fin, algo sabido en la Argentina, un país que en la debacle económica causada por el régimen macrista es golpeado por una pandemia global, sumada esta peste a la epidemia local del dengue, mientras un enorme asteroide se acerca a la tierra a fines de abril. Ni Hollywood se atrevió a tanto. Así, no hay realismo que aguante.

Bibliografía 
HÖGLUND, Johan (2017): "Eat the Rich: Pandemic Horror Cinema". En Transtext(e)s Transcultures 跨文本跨文化, Journal of Global Cultural Studies, 12 | 2017, The Other's Imagined Diseases. Transcultural Representations of Health.

LEÓN VEGAS, Milagros (2010): "Arte y peste: Desde el medievo al ochocientos, de la mitología a la realidad local". En Boletín de Arte, no 30-31, Departamento de Historia del Arte, Universidad de Málaga, 2009-2010: 223-238.

ROZARIO, Kevin (2007): The Culture of Calamity: Disaster and the Making of Modern America. University of Chicago Press. 